\title{
A HIPERVULNERABILIDADE DO CONSUMIDOR IDOSO NAS MENSALIDADES DOS PLANOS DE SAÚDE EM RAZÃO DA IDADE NA JURISPRUDÊNCIA REPETITIVA DO STJ (RESP 1.568.244/RJ)
}

http://dx.doi.org/10.21527/2176-6622.2019.51.34-48

Recebido em: 10/11/2018

Modificações requeridas em: 10/5/2019

Aceito em: 18/5/2019

Dennis Verbicaro

Doutorado em Direito do Consumidor pela Universidade de Salamanca (Espanha). Mestrado em Direito do Consumidor pela Universidade Federal do Pará. Professor da Graduação e dos Programas de Pós-Graduação Stricto Sensu da Universidade Federal do Pará-UFPA e do Centro Universitário do Pará-Cesupa. Procurador do Estado do Pará, Advogado e Diretor do Brasilcon. Líder de grupo de pesquisa (CNPq): Consumo e Cidadania. dennis@gavl.com.br.

Sergie Gerrits Arruda

Mestrando em Gestão pela Universidade de Coimbra, em Portugal. Membro do Departamento de Marketing e Comunicação da Júnior Empresa de Estudantes da Faculdade de Economia da Universidade de Coimbra (Jeefeuc). Graduação/Bacharelado em Direito pela Universidade Federal do Pará (Ufpa). Advogado. Participou do programa de intercâmbio TOP China 2016 na Peking University, financiado pelo Santander Universidades, ocasião em que foi premiado entre as melhores apresentações. Contemplado com o Prêmio Edson Luís de Excelência e Mérito em 2016. Contemplado com bolsa de estudos do DAAD (Deutscher Akademischer Austauschdienst) para realizar curso de inverno (Winterkurs) na Universidade de Duisburg-Essen, na Alemanha, em 2017. Possui experiência na área de Marketing, Business Intelligence e Línguas Estrangeiras. sergiearruda@gmail.com

\section{RESUMO}

O presente artigo, por meio do método dedutivo e de pesquisa teórica e jurisprudencial, pretende demonstrar que a decisão do Superior Tribunal de Justiça, no julgamento do tema repetitivo 952 e com base no REsp 1.568.244/RJ, a pretexto de padronizar a interpretação judicial acerca dos reajustes abusivos nas mensalidades dos planos de saúde do idoso, importou em grave retrocesso à tutela do consumidor, na medida em que supervalorizou o vetusto princípio do pacta sunt servanda nas relações de consumo e, ainda, atribuiu autoridade decisória irrecorrível à Agência Nacional de Saúde quanto ao reajuste das mensalidades, deixando para uma improvável revisão judicial o conceito de onerosidade excessiva na análise do caso concreto. Conclui-se que o precedente em referência ignora a condição de hipervulnerabilidade do consumidor idoso, favorecendo a transferência do risco da atividade econômica das Administradoras de Planos para a parte mais fraca na relação de consumo, comprometendo o próprio acesso à saúde.

Palavras-chave: Direito do consumidor. Hipervulnerabilidade do idoso. Planos de saúde. REsp 1.568.244/RJ. Superior Tribunal de Justiça.

THE HYPERVULNERABILITY OF ELDERLY CONSUMER IN THE MONTHLY PAYMENT OF THE HEALTH PLANS IN REASON OF THE AGE IN THE REPETITIVE JURISPRUDENCE BY STJ (RESP 1.568.244/RJ)

\section{ABSTRACT}

This article, through the inductive method and theoretical and jurisprudential research, intends to demonstrate that the decision of the Superior Court of Law, in the judgement of the repetitive theme 952 and based on the REsp 1.568.244/RJ, under the pretext of standardizing the judicial interpretation about the abusive readjustments of the monthly payment of elderlies' health insurances, resulted in a severe regression in consumer protection, in so far as it overvalued the old principle of pacta sunt servanda in consumer relations and, moreover, provided unappealable decision-making authority to the National Health Agency regarding the readjustment of monthly fees, leaving to an unlikely judicial review the concept of excessive onerousness in the analysis of the concrete case. It is concluded that the mentioned decision ignores the condition of hypervulnerability of the elderly consumer, favoring the transfer of the risk of the economic activity of the Health Plans to the weaker part in the consumption relation, compromising the own access to health.

Keywords: Consumer law. Hypervulnerability of the elderly. Health Plans. REsp 1,568,244 / RJ. Superior Court of Justice.

\section{SUMÁRIO}

1 Introdução. 2 Novos paradigmas do direito privado. 3 A tutela do consumo e políticas de igualdade. 4 A hipervulnerabilidade da pessoa idosa. 5 A tutela jurídica dos planos de saúde no Brasil. 6 Uma análise reflexiva acerca dos impactos jurídicos do julgamento do Recurso especial repetitivo (REsp 1.568.244/RJ) pelo STJ acerca da elevação das mensalidades dos planos de saúde em razão da faixa etária. 7 Conclusão. 8 Referências. 


\section{INTRODUÇÃO}

O direito do consumidor contemporâneo é fruto das rápidas transformações sociais e econômicas dos tempos atuais, tempos estes marcados também pelo consumo predatório, transferência do risco empresarial aos vulneráveis e o crescente abstencionismo estatal. Tem-se atualmente verdadeiro momento de mudanças na tutela jurídica dos bens considerados importantes em cada sociedade. Em outras palavras, identifica-se um preocupante retrocesso em relação às grandes conquistas consumeristas de décadas atrás.

O pós-guerra do século passado resultou em maiores preocupações com o ser humano e na alteração de como o direito enxerga o homem. É nesse contexto que os principais ramos do direito passam a ser observados por uma perspectiva que valoriza menos aspectos materiais e mais as pessoas, buscando proteger o ser humano com base no princípio denominado dignidade da pessoa humana e tentando, desta forma, diluir a existência da indústria de danos presente (MORAES, 2003, p. 64-68).

Tal princípio ensejou maior cuidado com o ser humano nas relações jurídicas e passou a ser fundamento do ordenamento jurídico de diversos países, incluindo-se aí o Brasil, conforme preceitua o artigo 10, inciso III, da Constituição Federal, por conta de sua maior preocupação com os princípios fundamentais espraiados ao longo de seu texto e com maior destaque em seus primeiros títulos.

Esta premissa é exatamente o que norteou o direito do consumidor na forma como foi concebido no ordenamento jurídico brasileiro, objetivando promover, de forma eficaz, a tutela do consumidor, parte vulnerável da relação de consumo, ante as inúmeras práticas lesivas e demais abusos praticados pelos agentes econômicos, a partir de uma lógica de desigualdades jurídicas de tratamento.

Neste particular, o movimento consumerista apresentou-se como uma espécie de contrapoder em relação aos agentes econômicos do mercado, sobretudo nos países com elevado grau de desenvolvimento. $O$ crescimento da produção, associado ao aumento da renda, fez com que se elevasse a capacidade de compra do cidadão. A despersonalização da atividade empresarial e a massificação do comércio, sobretudo no âmbito eletrônico, assim como a inserção das técnicas de convencimento publicitário e o marketing, favoreceram o surgimento de uma espécie de consciência defensiva perante os abusos do mercado.

Ademais, as exigências de segurança, boa-fé objetiva e transparência nas relações de consumo em meio a produtos e serviços com elevado grau de sofisticação, num mercado repleto de opções e informações deficientes, impuseram ao Estado e ao direito a criação de desigualdades jurídicas de tratamento, para amenizar as desigualdades fáticas do plano econômico entre consumidor e empresário.

Compreendeu-se que, ao exigir mais dos fornecedores quanto à qualidade e segurança dos bens de consumo, se estava favorecendo a própria profissionalização do mercado, elevando padrões de qualidade e garantindo melhores condições de competitividade, ou seja, todos ganhavam com o reconhecimento jurídico da nova categoria: o consumidor. Isso, mais tarde, visto sob uma perspectiva transindividual, consolidou a tutela dos interesses pertencentes a toda a coletividade.

A tutela jurídica dos interesses do consumidor no Brasil, portanto, expressou o rompimento com toda a tradição individualista do direito privado, ilustrou o compartilhamento da autoridade estatal com a sociedade civil, por meios da abertura e do estímulo à ocupação dos novos espaços políticos de deliberação, como também tentou reposicionar a liberdade decisória da coletividade de consumidores em relação aos detentores dos meios de produção, seja mediante a difusão de novos deveres éticos aos fornecedores de produtos e serviços, ou da menor influência sofrida pela indústria cultural (massificada pelas mídias e que corrói a identidade autônoma do sujeito), a partir dos instrumentos de proteção jurídico-políticos previstos na legislação. Isso tudo gerou um ciclo virtuoso de proteção jurídica do consumidor como categoria política, ou seja, o fortalecimento jurídico-político do consumidor fomentou a construção de um modelo mais amplo de cidadania numa democracia participativa.

Observa-se, entretanto, uma preocupante mudança de rumo, pois vive-se em tempos sombrios no âmbito das relações de consumo, posto que a precarização da tutela jurisdicional vem comprometendo a confiança no Judiciário e, ao mesmo tempo, passa a mensagem perigosa ao segmento empresarial de que compensa agir na infralegalidade, até porque o próprio Estado-Administração, em sua função regulatória dos serviços públicos, há muito, deixou de ser um mediador responsável no mercado de consumo, sobretudo no âmbito da saúde suplementar. 
Outrossim, nota-se que certos grupos da sociedade ocupam posição de vulnerabilidade agravada nas relações de consumo, também denominada de hipervulnerabilidade. Nesse sentido, o presente artigo busca estudar a posição jurídica do consumidor idoso e o reconhecimento de sua hipervulnerabilidade quando da utilização de planos de saúde, objetivando identificar em que nível o desequilíbrio entre as partes contratantes deste serviço pode resultar no aprofundamento do abismo econômico entre os sujeitos.

Um Estado liberal e abstencionista não reconhece nitidamente todas as categorias sociais, principalmente aquelas com maior grau de debilidade econômica, por exemplo, os trabalhadores e os portadores de necessidades especiais, tampouco o consumidor, ainda mais quando idoso. Como também dependem das pretensas virtudes da representação política e como essa habitualmente despreza a minoria, as categorias citadas ficarão à margem de um reconhecimento mínimo quanto à sua expressão e direitos, mas, muitas vezes, por também se iludirem em relação à pseudoigualdade propagada, não percebem tal distorção no modelo democrático, muito menos se sentem impelidos a exigir mudanças.

O direito, sob o viés regulatório, é nitidamente individualista e, por supervalorizar a vontade como principal fonte obrigacional, não é capaz de reconhecer no plano normativo as desigualdades econômicas e sociais que impedem a manifestação de vontade verdadeiramente livre do consumidor, do trabalhador e de outras categorias marginais, que, em razão da coação econômica que sofrem, muito facilmente renunciam aos seus direitos mais básicos, sobretudo àqueles que guardam pertinência com sua dignidade e incolumidade.

Nesse sentido, para justificar a necessidade de mudança no perfil do direito, será preciso rever o conceito de coação econômica para incluir a exploração da vontade daquele que se encontra numa situação de vulnerabilidade e hipossuficiência e que, em razão de uma inexorável necessidade básica, se vê obrigado a ceder em suas expectativas, interesses e direitos para satisfazê-la e, o que é pior, sob o manto de uma pretensa legitimidade jurídica.

O presente artigo pretende demonstrar, usando o método indutivo e de pesquisa teórica e jurisprudencial, que a decisão do Superior Tribunal de Justiça (STJ), no julgamento do tema repetitivo 952 e com base no REsp 1.568.244/RJ, a pretexto de padronizar a interpretação judicial acerca dos reajustes abusivos nas mensalidades dos planos de saúde do idoso, importou em grave retrocesso à tutela do consumidor, na medida em que convalidou o vetusto princípio do pacta sunt servanda nas relações de consumo e, ainda, atribuiu autoridade decisória irrecorrível à Agência Nacional de Saúde (ANS) quanto ao reajuste das mensalidades, deixando para uma improvável revisão judicial o conceito de onerosidade excessiva na análise do caso concreto.

Para se alcançar a conclusão supra, o artigo foi dividido em sete capítulos, incluindo-se a introdução e a conclusão. No segundo capítulo é apresentada a transição de paradigmas no âmbito do direito privado, sobretudo pela assimilação de bases mais solidárias, em que haveria uma maior valorização do homem em substituição ao viés patrimonialista. No terceiro capítulo se falará da tutela normativa do consumidor e das diferentes acepções do princípio da igualdade nas relações de consumo, sobretudo da vedação ao tratamento discriminatório em relação ao idoso. No quarto capítulo será desenvolvida a ideia de hipervulnerabilidade (vulnerabilidade agravada) do idoso, a justificar uma proteção jurídica especial em seu favor. No quinto capítulo abordar-se-á o regramento dos planos de saúde no Brasil. No sexto capítulo serão analisados os impactos da decisão do Superior Tribunal de Justiça (STJ) no julgamento do REsp 1.568.244/RJ atinente aos critérios de reajuste nas mensalidades dos planos de saúde, em especial em relação ao consumidor idoso.

\section{NOVOS PARADIGMAS DO DIREITO PRIVADO}

A mudança no foco do direito em âmbito constitucional, que passou a cuidar mais da pessoa em detrimento dos bens, provocou notáveis reflexos no direito privado, agora influenciado por doutrinas derivadas de uma nova ótica que se centra na figura do ser humano, a qual busca na Constituição balizas e respostas para seus problemas (TEPEDINO, 2005, p. 2). Tal fato implicou uma poderosa mudança paradigmática no direito privado e em seus mais variados institutos.

O Código Civil de Beviláqua, de viés liberal-individualista, não mais era capaz de satisfazer os anseios de uma sociedade que almejava por proteção, sobretudo de um Estado que prometia bem-estar social e um maior comprometimento com políticas de igualdade e solidariedade, o que repercutiu numa feição mais plural do direito. Tal contexto foi justamente o que engendrou o paradigma contemporâneo do direito privado, calcado na tutela do ser humano, pelo humano e para o humano. 
Chaves de Farias, Rosenvald e Braga Netto (2015, p. 4-10) são claros ao denotar que os avanços sociais geraram uma verdadeira sociedade de risco, marcada por profundas incertezas, e, para conferir adequada proteção aos direitos de uma sociedade de risco, faz-se necessária uma responsabilidade civil que responda satisfatoriamente para esses novos riscos.

Nesse sentido, seriam princípios da responsabilidade civil: a Dignidade da Pessoa Humana, a solidariedade, a prevenção e a reparação integral. Em outras palavras, a responsabilidade civil contemporânea deve prezar pela resolução dos conflitos de modo que os direitos possuam uma ampla e completa tutela e a pessoa humana seja priorizada, prezando-se por políticas que assegurem a dissuasão e previnam a ocorrência de práticas lesivas aos mais diferentes bem jurídicos, buscando um direito privado solidário e sensível aos direitos, principalmente dos mais vulneráveis (CHAVES DE FARIAS; ROSENVALD; BRAGA NETTO, 2015, p. 16-31).

Na mesma linha de pensamento, Schreiber (2013, p. 227-229) reconhece o debate atual sobre prevenção e precaução na responsabilidade civil, pois tem-se que a ideia de evitar o dano gradativamente toma o lugar da ideia de repará-lo. Assim, a função clássica de compensação passa a perder o foco, deixando a clássica responsabilidade individualista de lado para se adotar uma responsabilidade social, calcada, sobretudo, na ideia de solidariedade. Para Cavalieri Filho (2012, p. 511),

A responsabilidade civil nas relações de consumo é a última etapa dessa longa evolução da responsabilidade civil. Para enfrentar a nova realidade decorrente da Revolução Industrial e do desenvolvimento tecnológico e científico, o Código do Consumidor engendrou um novo sistema de responsabilidade civil para as relações de consumo, com fundamentos e princípios novos, porquanto a responsabilidade civil tradicional revelara-se insuficiente para proteger o consumidor.

Foi como resposta a essas mudanças que o direito positivo empenhou esforços para se adequar, e é com base nestes ideais que as legislações de direito privado modernas surgem, como o Código Civil de 2002 e o Código de Defesa do Consumidor. Vive-se um momento em que se reconhece um verdadeiro direito civil-constitucional, pois a eficácia horizontal dos direitos fundamentais ganha amplo relevo e seus princípios passam a permear as relações privadas.

A Constituição Federal de 1988, em vários dos seus artigos, trouxe as primeiras regras de proteção ao consumidor. São eles: artigo 5o, inciso XXXII, ${ }^{1}$ artigo $24, \mathrm{VIII}^{2}$ artigo $150, \S 5^{\circ},{ }^{3}$ artigo 170 , inciso $\mathrm{V}^{4}$ e artigo 175 , parágrafo único, $1 I^{5}$. Todas essas normas têm seu grau de relevância para a tutela consumerista, porém as que têm maior e mais direta inflexão sobre o fenômeno são os artigos $5^{\circ}$, XXXII e 170, V, porque são as normas de natureza principiológica. No primeiro caso, tem-se a proteção do consumidor como um dos direitos fundamentais do indivíduo. Já no capítulo da ordem econômica, vê-se a preocupação com o consumidor equiparada a outros princípios, como a livre-iniciativa e a livre-concorrência, na mesma condição de base fundamental dessa organização normativa.

3 “Art. 150 - Sem prejuízo de outras garantias asseguradas ao contribuinte, é vedado à União, aos Estados, ao Distrito Federal e aos Municípios: [...]

$\S 5^{\circ}$ A lei determinará medidas para que os consumidores sejam esclarecidos acerca dos impostos que incidam sobre mercadorias e serviços."

4 "Art. 170 - A ordem econômica, fundada na valorização do trabalho humano e na livre iniciativa, tem por fim assegurar a todos existência digna, conforme os ditames da justiça social, observados os seguintes princípios:

$[\ldots]$

V- defesa do consumidor." (grifo nosso).

"Art. 175 - Incumbe ao Poder Público, na forma da lei, diretamente ou sob regime de concessão ou permissão, sempre através de licitação, a prestação de serviços públicos.

Parágrafo único. A lei disporá sobre:

$[\ldots]$

II - os direitos dos usuários;"
} 
Tem-se, portanto, o enquadramento da proteção do consumidor em duas situações diferenciadas: uma com a proteção individual e coletiva do consumidor, enquanto direito fundamental, e outra como um dos alicerces da própria ordem econômica. Neste particular, emerge uma indagação: Como é possível compatibilizar a proteção do consumidor com a livre-iniciativa, pois ambos têm a mesma hierarquia, estão enquadrados no mesmo dispositivo constitucional (art. 170), mas possuem conteúdos normativos aparentemente antagônicos?

A partir do momento em que o direito do consumidor consegue compatibilizar esses dois princípios, o legislador infraconstitucional se sentirá à vontade para criar um código, sistematizando toda essa proteção, surgindo, então, o Código de Defesa do Consumidor (CDC), Lei no 8.078/1990. Nesse sentido, é possível afirmar que o CDC surge a partir de uma necessidade de pragmatização dessa principiologia constitucional.

Construiu-se, portanto, um direito privado solidário, empático e preocupado com as questões que podem impactar as camadas sociais, noção bem-desenvolvida pelo direito germânico com o termo solidarprivatrecht, ideal que deve acompanhar o direito privado em todos seus desdobramentos (MUCELIN, 2016, p. 137).

O comportamento errático do Estado na consecução das políticas públicas de proteção do consumidor e a postura desumanizada do Judiciário numa crescente banalização das pretensões consumeristas, entretanto, sinalizam no sentido inverso: de precarização da tutela jurídica do consumidor e num maior nível de indiferença em relação aos grupos hipervulneráveis, como o idoso, a despeito de sua dupla proteção pelo CDC e pela Lei 10.741/2003 (Estatuto do Idoso), conforme se verificou no julgamento do Recurso Especial (REsp 1.568.244/RJ).

\section{A TUTELA DO CONSUMO E POLÍTICAS DE IGUALDADE}

Conforme demonstrado supra, a proteção jurídica diferenciada do consumidor pauta-se justamente na relativização do princípio da igualdade e na necessária criação das desigualdades jurídicas de tratamento em razão de sua vulnerabilidade econômica ante os detentores dos meios de produção. Surge, também, como resposta aos novos paradigmas do direito privado, de modo a salvaguardar especificamente os direitos oriundos de uma sociedade assediada por um modelo de consumo predatório e insustentável.

A sociedade consumerista atual é fruto do largo desenvolvimento tecnológico dos meios de produção, transporte e comunicação, os quais possibilitaram a redução das fronteiras e a fruição da atividade comercial numa perspectiva transnacional. Consequentemente, o consumo também se tornou um meio pelo qual o risco da atividade econômica se propaga e, muitas vezes, é revertido em desfavor do consumidor.

Assim, o grande estímulo ao consumo desenfreado e o crescimento desregulado do capitalismo ensejou uma grande quantidade de danos dentro da sociedade, um fato jurídico sobre o qual o Direito não poderia se quedar inerte.

Com efeito, este panorama de consumo em escala global e indústria cultural dá azo a um cenário marcado pela figura do consumidor-comunidade global, caracterizando uma cultura do consumo que rompe os limites geográficos e dita os modelos estéticos e de comportamento em uma vasta gama de países, por mais diferentes que sejam histórica e economicamente.

O enraizamento do fenômeno é forte a ponto de influenciar a própria cultura de grupos sociais, estabelecendo hábitos e estimulando comportamentos, fenômeno esse particularmente visível ao se analisar o papel das tecnologias de comunicação na sociedade, quando o consumo de certos itens se torna um fator de interação e inclusão social, fazendo com que o indivíduo busque o reconhecimento e a inserção em um certo grupo por meio de determinadas formas de consumo que caracterizam o sentimento de pertencimento deste grupo (SOMMER, 2007, p. 17-18). A resposta dos Estados às práticas abusivas torna-se eficaz na medida em que a noção de solidariedade é incorporada aos institutos jurídicos.

A indústria cultural emerge do desenvolvimento de mecanismos de controle das consciências individuais e coletivas, exercidos pelos meios de comunicação em massa, tais como rádios, televisão, cinema, jornais, revistas, etc., os quais não se preocupam em reproduzir fidedignamente a cultura espontânea produzida na sociedade, mas, sim, padronizar e adaptar as massas aos valores capitalistas de consumo, criando, de for- 
ma explícita ou subliminar, necessidades de consumo crescentes, por meio de um aprimorado processo de racionalização dos meios de produção, padronização, difusão e divulgação de bens de consumo como produtos culturais.

Revela-se como inegável, também, o fato de que o comércio em escala mundial se despersonalizou e os grandes grupos econômicos multinacionais desenvolveram melhores ferramentas para forjar necessidades de consumo globais, ou seja, para estimular e vincular psicologicamente o consumidor a adquirir novos bens de consumo, financiam uma indústria cultural concebida para moldar os gostos, predileções, senso estético e, por que não dizer, o "modelo ideal de qualidade de vida e realização pessoal" do consumidor para o mundo globalizado, habilidade essa tão bem desenvolvida que o grau de penetração dessa abordagem transnacional não discrimina países ocidentais de orientais, desenvolvidos de subdesenvolvidos, de economia liberal de intervencionistas, produzindo um diálogo universal em relação a todos. Daí exsurge a identidade fática desse novo conceito, pois toda a coletividade, mundialmente considerada, estará exposta, por intermédio do mesmo marketing, a iguais bens de consumo, nem sempre adequados, nem sempre seguros ou nem sempre vendidos em condições transparentes e equitativas ao consumidor.

A imposição de padrões culturais com forte apelo consumista em escala global é consequência lógica do advento da técnica na ciência moderna, uma vez que o desenvolvimento tecnológico trouxe a reboque a ruína progressiva da cultura teórica e da autorreflexão do pensamento, a autodestruição do esclarecimento e a consequente massificação de comportamentos de consumo erráticos e padronizados.

Modelos de consumo são apresentados no mercado a pretexto de representarem os reais anseios do grupo, mas que, na verdade, se justificam pela maior probabilidade de lucro e sucesso de vendas, jamais pela qualidade intrínseca do bem em seu valor funcional, segurança ou singularidade (SOMMER, 2007, p. 79-82).

Com o intuito de resolver a situação, os diplomas legais consumeristas, com amparo maior no texto constitucional vigente, buscam estipular medidas adequadas para tutelar o consumo e garantir ao mesmo tempo o exercício da atividade econômica e livre-iniciativa, tentando encontrar o equilíbrio com a proteção ao consumidor por meio de medidas restritivas e protecionistas.

Neste sentido, a Constituição Federal conferiu proteção particular aos direitos do consumidor, observados principalmente nos artigos 50, XXXII, e 170, V, os quais, sendo normas principiológicas, estipulam a defesa do consumidor como direito fundamental do indivíduo e fundamento da ordem econômica, respectivamente. Embora os interesses econômicos e sociais possam acabar por se antagonizarem em diversos momentos, 0 encontro devido do equilíbrio é fundamental e deve ser alvo do direito do consumidor, uma vez que tais interesses são considerados relevantes no ordenamento jurídico brasileiro (VERBICARO, 2009, p. 80-82).

O legislador brasileiro foi muito feliz ao elaborar um Código bastante analítico, ou seja, trata-se de uma lei que não se limita apenas a estabelecer normas de conduta. É uma norma que também forma princípios, conceitos e permite a fácil identificação dos elementos da relação jurídica de consumo, justamente para garantir sua maior amplitude e consequente eficácia social.

Caso fosse diferente, se o Código não estabelecesse quem seria o consumidor ou o fornecedor, ficaria muito mais fácil para este último criar mecanismos de exoneração ou limitação de responsabilidade, como também obstáculos ao seu enquadramento como tal. Nesse sentido, com a redação clara dada pelo CDC, essas dúvidas desaparecem. É certo que a função de um Código não é conceituar, mas o legislador brasileiro buscou essa conceituação, justamente para garantir a melhor eficácia da tutela em sua maior amplitude.

O poder de vinculação de uma norma de direito do consumidor é um dos mais contundentes, levando-se em conta que intervém na relação jurídica de que faz parte uma categoria específica, merecedora de tratamento jurídico diferenciado, apresentando uma validade cogente, que a faz prevalecer em relação às demais normas do sistema pelo próprio critério da lex especialis na solução de eventuais antinomias, até porque também há alicerce constitucional nessa tutela.

Destarte, quando se fala de consumidor, a primeira característica a se revelar no conceito é a vulnerabilidade, então entendida como uma presunção absoluta inerente a todo e qualquer consumidor, pautada na ideia de inferioridade econômica em relação ao fornecedor, por não dispor do controle dos meios de produção. 
Alguns consumidores, além da vulnerabilidade, têm a hipossuficiência como característica, razão pela qual esta será entendida como um conceito relativo, na medida em que vai legitimar tratamento processual distinto em favor destes face a face com os fornecedores. Além do direito material, que já é especialmente prolífero em benefícios, há também uma proteção formal para garantir que esse direito material seja instrumentalizado por meio de um processo equilibrado e que democratize o acesso à justiça.

Não se pode perder de vista que, ao contrário do consumidor, o fornecedor é um litigante contumaz, que já está habituado a criar obstáculos processuais que inviabilizem e retardem a discussão judicial do conflito. Essa hipossuficiência, contudo, não se confunde com o caráter instrumental do processo, que vai estar presente em toda e qualquer relação de consumo, seja o consumidor hipossuficiente ou não, embora com tal instrumentalidade se relacione, na medida em que ambos buscarão a entrega da prestação jurisdicional de uma maneira célere e satisfatória ao consumidor.

O legislador brasileiro não se limitou a apresentar um único conceito de consumidor. A lei traz expressamente quatro, a saber: artigo $2^{\circ}$, caput (destinatário final), artigo $2^{\circ}$, parágrafo único (coletividade que haja intervindo nas relações de consumo e controle coletivo concreto), artigo 17 (vítima do evento/bystander) e artigo 29 (coletividade exposta às práticas empresariais abusivas). Esses conceitos vão englobar tanto pessoas físicas quanto jurídicas, disciplinando a relação jurídica do ponto de vista individual ou do ponto de vista coletivo, seja concreto, ou, até mesmo, abstrato, porque serão contemplados os direitos coletivos stricto sensu, individuais, homogêneos, difusos e há, inclusive, um conceito transnacional: consumidor comunidade-global. Tais conceitos favorecem a perfeita identificação, numa determinada relação jurídica, se determinada empresa, ou determinado indivíduo, poderá ou não utilizar o CDC para defender os seus interesses.

Como antecipado supra, haverá uma presunção de vulnerabilidade do consumidor, atributo fundamental para a análise do problema discutido, sobretudo da promoção da igualdade, pois é o ponto de partida do tema e é precisamente de onde se irradiam muitos dos institutos do direito do consumidor.

Trata-se de presunção jure et de jure, ou seja, absoluta, de que o consumidor não dispõe de igualdade ao tratar com o fornecedor, uma vez que este último dispõe usualmente de grandes aparatos e meios financeiros, técnicos e jurídicos que o põem em posição de superioridade para resolver seus problemas, principalmente nos dias atuais, uma vez que existem empresas com tamanho poder que transcendem continentes e são mais poderosas que alguns Estados. Isso se evidencia claramente com a elaboração de contratos de adesão, quando o consumidor não discute suas cláusulas, cabendo apenas sua aceitação, ou, ainda, em matéria probatória sobre certos assuntos, pois resta evidente que são inúmeras as situações em que apenas a empresa possui condições de demonstrar determinados fatos (MUCELIN, 2016, p. 133-134).

No permanente processo de aprimoramento do direito do consumidor, identificou-se determinados grupos da sociedade em condição agravada de vulnerabilidade, condições peculiares que evidenciavam desvantagem acima da média por conta de características particulares intrínsecas, ou decorrentes de fatores extrínsecos.

No primeiro caso, é possível citar os idosos, as crianças, os deficientes, entre outros grupos, os quais se diferenciam pela presença de características intrínsecas, como a fragilidade física, emocional, desenvolvimento mental ou cognitivo incompleto, etc. No caso de fatores extrínsecos, tem-se a mulher como vítima do assédio discriminatório de gênero ${ }^{6}$ e o consumidor superendividado, ou mesmo a vulnerabilidade situacional do consumidor no âmbito do comércio eletrônico. A estes grupos atribuiu-se o termo hipervulnerabilidade, pois são consumidores que, pelas suas condições particulares, merecem tutela ainda mais diferenciada.

\section{A HIPERVULNERABILIDADE DA PESSOA IDOSA}

Dentro dos grupos de consumidores hipervulneráveis, merece especial atenção a figura do consumidor idoso. É fato indubitável que a condição de idoso é acompanhada de dificuldades no pleno exercício das faculdades, especialmente no que diz respeito às condições de saúde. A capacidade de raciocínio, locomoção,

Sobre o tema, sugere-se a leitura do artigo: VERBICARO, Dennis; ALCÂNTARA, Ana Beatriz. A percepção do sexismo face à cultura do consumo e a hipervulnerabilidade da mulher no âmbito do assédio discriminatório de gênero. Revista Pensamento Jurídico, São Paulo, v. 11, n. 1, jan./jun. 2017. 
labor e diversas outras são gradativamente afetadas pela inevitável degeneração causada pelo curso do tempo, fato jurídico a que todos estão sujeitos. Foi a partir dessas noções que surgiu o conceito de solidariedade intergeracional.

A proteção conferida ao idoso encontra vasta guarida no ordenamento jurídico nacional, ao iniciar pela Constituição Federal, segundo a qual, em seu título VIII, Capítulo VII, e em especial no artigo 230, determina que é dever da família, da sociedade e do Estado "amparar as pessoas idosas, assegurando sua participação na comunidade, defendendo sua dignidade e bem-estar e garantindo-Ihes o direito à vida". Com base neste norte, o Estatuto do Idoso surge como dispositivo legal para efetivar ainda mais os direitos da pessoa idosa.

Cabe destacar que um dos principais aspectos concernentes à vulnerabilidade do idoso é o aspecto psíquico. A indústria cultural desenvolveu-se de tal forma a criar um sistema nocivo de incentivo ao consumo desmedido, utilizando-se de artifícios, inclusive de natureza psicológica, para criar maior apelo a seus produtos e necessidades artificiais de consumo. Assim, a vulnerabilidade psíquica do idoso implica maior suscetibilidade aos apelos da indústria cultural, tornando-o mais vulnerável a comprar produtos, adquirir serviços, aderir a cláusulas que criam falsos benefícios, etc. (DIAS, 2015, p. 287-289). Todos estes fatos contribuem para outra dificuldade que assola a vida da pessoa idosa, que são as dificuldades financeiras e o superendividamento.

Tal análise torna-se particularmente importante quando se busca encontrar em que medida estes impactos econômicos podem se tornar juridicamente relevantes. Segundo dados do IBGE de 2015, nesse ano havia 29.374 idosos no país, o que representa $14,3 \%$ da população nacional, indicador que aponta um aumento de idosos, uma vez que em 2014 esses representavam 13,7\%. A expressão de idosos no país pode ainda ser ressaltada com os dados da World Health Organization (WHO), de 2016, a qual mostra que a expectativa de vida do brasileiro em 2015 foi de 75 anos de idade, denotando uma tendência de aumento.

Outros dados relevantes ao presente estudo dizem respeito aos aspectos financeiros dos idosos e seu papel atual no Brasil. Analisando a posição econômica do idoso, Santana e Lima (2012, p. 184-185), com apoio em diversos órgãos estatísticos, revelam que há um crescente papel do idoso como arrimo financeiro das famílias brasileiras, desempenhando atuação fundamental na renda familiar. De acordo com o estudo, em 2009 os idosos eram pessoas de referência no orçamento familiar em $64,1 \%$ dos domicílios em que residem. Prosseguem os autores com a análise de que o envelhecimento somente se torna fator relevante de afastamento da contribuição na renda familiar a partir dos 80 anos de idade. Areosa $(2015$, p. 174$)$ ratifica o papel relevante da pessoa idosa nas finanças domésticas, destacando dados de que a proporção de famílias que possuem idosos como chefes e filhos morando juntos tem sido crescente, chegando a representar $45 \%$ em 2007.

Essa fragilidade financeira do idoso agrava sua vulnerabilidade diante de práticas abusivas e compromete a satisfação de suas necessidades existenciais. No Brasil, a pessoa idosa, diante das já apontadas formas de hipervulnerabilidade, é uma das principais vítimas do fenômeno do superendividamento, caracterizado pela impossibilidade de arcar com suas despesas atuais e futuras, gerando uma situação grave de inadimplemento, insolvência e uma sequência de dificuldades financeiras daí oriundas (FIGUEIREDO; SILVA JÚNIOR, 2012, p. 16-21). A partir deste ponto, inúmeras consequências, como o sentimento de vergonha e constrangimento, além das pressões familiares decorrentes do papel do idoso nas economias domésticas, geram um problema notório, situação agravada ainda pela dificuldade em lidar com os problemas inerentes à idade avançada.

A situação do consumidor idoso, portanto, é delicada e caracterizada por uma hipervulnerabilidade que precisa ser observada com cautela pelo Judiciário, sob risco de gerar fenômenos sociais com grandes repercussões negativas e danos em larga escala, sob a luz dos argumentos supraesposados.

\section{A TUTELA JURÍDICA DOS PLANOS DE SAÚDE NO BRASIL}

Tecidas as considerações sobre a posição do idoso como indivíduo hipervulnerável nas relações de consumo em um contexto de direito privado solidário, passa-se a analisar a tutela normativa dos planos de saúde no Brasil. 
Naturalmente, a idade avançada da pessoa idosa implica necessidade de maiores cuidados com sua saúde. Este é um período no ciclo da vida em que os componentes do corpo humano não mais desempenham suas funções como outrora, deixando o indivíduo fragilizado, com sua saúde muito mais sensível, motivo pelo qual a pessoa idosa passa a utilizar e depender de serviços de saúde mais do que em qualquer outro período da vida.

A tutela dos planos de saúde, contudo, frequentemente se mostra objeto de críticas e explicita uma falha a ser observada. Em estudo notável sobre a utilização de planos de saúde, Vieira Júnior (2013, p. 5960) demonstra que, no período entre 2010 e 2012, na Região Sudeste do país, os índices de reclamações de planos de saúde são expressivamente maiores entre os beneficiários acima de 60 anos, chegando ao ponto de que o coeficiente de reclamações destes é quase o dobro em relação ao coeficiente dos que se encontram entre 20 e 59 anos de idade. Tais dados revelam a ideia de que a tutela do direito à saúde das pessoas idosas encontra dificuldades notórias no Brasil.

Ocorre ainda que a utilização destes serviços frequentemente se torna inviabilizada em razão da elevação abusiva dos valores de mensalidades de planos de saúde privados. Tem-se atualmente os direitos à vida, saúde, integridade psicofísica e outros direitos corolários como principais alicerces do direito solidário, o qual se busca atualmente, fato decorrente das evoluções históricas já apontadas. Nessa linha de pensamento, Branco (2009, p. 400) ensina que o direito à vida não compreende simplesmente o direito de viver, mas inclui o direito de viver dignamente, isto é, com todas as condições que permitam à pessoa em determinada sociedade exercer suas vontades e direitos, gozando de saúde, bem-estar e outras características necessárias para o bom desenvolvimento da vida, tudo de acordo com as peculiaridades desta sociedade. $\mathrm{O}$ autor (2009, p. 393) prossegue ainda com a ideia de que:

A existência humana é o pressuposto elementar de todos os demais direitos e liberdades dispostos na Constituição. Esses direitos têm nos marcos da vida de cada indivíduo os limites máximos de sua extensão concreta. $O$ direito à vida é a premissa dos direitos proclamados pelo constituinte; não faria sentido declarar qualquer outro se, antes, não fosse assegurado o próprio direito de estar vivo para usufruí-lo. O seu peso abstrato, inerente à sua capital relevância, é superior a todo outro interesse.

Com base nessa ótica, entende-se que serviços de saúde privados, por tratarem de um aspecto tão fundamental que é a vida, jamais poderão se furtar de observar os preceitos sociais envolvidos em seu trabaIho, ensejando sempre o cuidado apropriado com os direitos tutelados. Limita-se aqui a autonomia privada para se assegurar a efetivação do direito humano à vida. Este é o entendimento do artigo 51 e dispositivos seguintes do CDC, os quais determinam como nulas as cláusulas que impliquem prática abusiva e permitam a alteração unilateral de serviços.

A atuação do Judiciário demonstra-se fundamental para coibir a prática de atos ilícitos e garantir que um direito tão importante seja resguardado por meio do mais amplo leque de ferramentas possíveis, uma vez que outros órgãos, como a Agência Nacional de Saúde Suplementar (ANS), que é responsável pela regulamentação do setor, já encontrou diversas falhas na matéria, como em casos de problemas de fiscalização (BRÊTAS, 2015; ANS, 2012), inadequação de medidas punitivas (PROTESTE, 2015), avaliações qualitativas falhas (CONSELHOS, 2012), entre outras.

O Judiciário, entretanto, não se preparou para a massificação das demandas de consumo, que são consequência natural da própria proliferação das práticas abusivas. As ações aventureiras são a exceção, mas tratadas como regra no processo de distanciamento do Estado jurisdicional em relação ao consumidor, agora visto como um litigante interesseiro, ${ }^{7}$ ou mera estatística de um julgamento desumanizado, e não como titular de direitos.

A fim de corroborar a afirmação supra, o Conselho Nacional de Justiça (CNJ) emite um relatório anual sobre a atividade do Judiciário no Brasil: o relatório "Justiça em Números" (CNJ, 2016), dentre uma série de estatísticas analisadas e sistematizadas nos mais diversos níveis do Poder Judiciário brasileiro. Nesse contexto,

Sobre o preconceito sofrido pelo consumidor em suas demandas judicias, vide: VERBICARO, Dennis; PENNA, João Vitor; LEAL, Pastora. O mito da indústria do dano moral e a banalização da proteção jurídica do consumidor pelo judiciário brasileiro. Revista de Direito do Consumidor, v. 114, ano 26, p. 75-99, nov./dez. 2017. 
exemplifica-se que as indenizações por dano moral no Direito do Consumidor correspondem ao quarto maior assunto em número de demandas em todo o Poder Judiciário brasileiro, correspondendo a 3,94\% (1.667.654 de processos) de todos os processos ingressados no Poder Judiciário no ano de 2015.

Em que pese o crescimento dessas demandas, a resposta judicial tende a ser no sentido de aviltar as indenizações, ou mesmo ignorar a violação a bens jurídicos relevantes do consumidor sob o falso pretexto de se coibir a famigerada "indústria do dano moral", fenômeno cuja inexistência se provou empiricamente a partir da pesquisa conduzida por Flavia Püschel (2011, p. 395), que concluiu:

Dentre as informações coletadas, constatou-se que as indenizações que ultrapassam o valor de $\mathrm{R} \$ 100.000,00$ (cem mil reais) não passam de $3 \%$ de todos os casos coletados, tendência esta que se repete nos tribunais (Tribunais de Justiça, Tribunais Regionais do Trabalho e Tribunais Regionais Federais) quando individualizados.

Interpretações pautadas no senso comum, exigências de produtividade e a falta de uma maior sensibilidade jurídica no julgamento das demandas de consumo, acabaram por desfigurar a atuação do Judiciário, precarizando o tratamento processual da parte vulnerável e, por consequência, menosprezando os bens jurídicos do consumidor, sobretudo quando identificada sua hipervulnerabilidade na dificuldade de fruição de serviços essenciais como aqueles prestados pelas administradoras de planos de saúde.

\section{UMA ANÁLISE REFLEXIVA ACERCA DOS IMPACTOS JURÍDICOS DO JULGAMENTO DO RECURSO ESPECIAL REPETITIVO (RESP 1.568.244/RJ) PELO STJ ACERCA DA ELEVAÇÃO DAS MENSALIDADES DOS PLANOS DE SAÚDE EM RAZÃO DA FAIXA ETÁRIA}

Com base na ótica até aqui exposta, o operador do direito deve ter cuidado ao analisar casos em que se depara com o aumento de valor de mensalidade em planos de saúde privados de idosos. 0 artigo 15, §3 do Estatuto do Idoso, o qual veda a discriminação do idoso nos planos de saúde pela cobrança de valores diferenciados em razão da idade, ensejou a criação de nova regulação acerca das faixas etárias nos planos por parte da Agência Nacional de Saúde Suplementar, inspirando sua Resolução Normativa 63/2003, que atualmente estipula a existência de 10 faixas etárias, sendo a maior a partir dos 59 anos, e determina algumas regras que acarretam aumentos desproporcionais, proibindo, assim, qualquer nova majoração a partir dos 60 anos.

Como observa Schmitt (2016, p. 1), o STJ possuía entendimentos amplamente divergentes, tanto no sentido de permitir quanto de negar a possibilidade de qualquer reajuste para os consumidores idosos, citando o REsp 809.329/RJ, de relatoria da ministra Nancy Andrighi, entre os notáveis acórdãos que negavam a possibilidade de reajuste até mesmo de contratos anteriores ao Estatuto do Idoso. É importante salientar que a jurisprudência repudia também o aumento daqueles próximos de completar 60 anos, na faixa de 58 ou 59 anos (GALESCO, 2014, p. 1). Nessa mesma linha interpretativa, cite-se a Apelação Cível 2012213713/SE e o Agravo 3633816/PE.

Alguns julgados um pouco mais antigos são claros no que diz respeito à abusividade do reajuste de valor do plano em decorrência da mudança da faixa etária, citando, inclusive, posicionamento do STJ (BRASIL, 2011, grifo nosso):

EMENTA: APELAÇAO CÍVEL - AÇÃO REVISIONAL DE PLANO DE SAÚDE - PRELIMINAR REJEITADA - DESNECESSIDADE DE PRODUÇAO DE PROVA - JULGAMENTO ANTECIPADO DA LIDE - LIVRE CONVENCIMENTO DO MAGISTRADO - ACERVO DOCUMENTAL SUFICIENTE - NÃO OCORRÊNCIA DE CERCEAMENTO DE DEFESA - REAJUSTE DE VALORES DE PLANO DE SAÚDE EM DECORRÊNCIA DE MUDANÇA DE FAIXA ETÁRIA - APLICABILIDADE DO CDC, DA LEI 9.656/98 E DO ESTATUTO DO IDOSO - VEDADA A DISCRIMINAÇAO EM RAZÃO DA IDADE - ABUSIVIDADE RECONHECIDA - PRECEDENTES DO STJ E DESTE TRIBUNAL - PREQUESTIONAMENTO - RECURSO CONHECIDO E IMPROVIDO (TJ-SE - AC: 2011214806 SE, Relator: DES. OSÓRIO DE ARAÚJO RAMOS FILHO, Data de Julgamento: 11/10/2011, 2a CÂMARA CÍVEL).

A jurisprudência recente do STJ, entretanto, invertendo a perspectiva de julgamento até então construída, adotou perigosa linha de interpretação em desfavor do consumidor idoso. 
A grande quantidade de recursos repetitivos versando sobre o assunto, levou ao tema repetitivo 952 , com base no REsp 1.568.244/RJ, ${ }^{8}$ o qual buscou encerrar a discussão, decidindo no sentido de que é possível o referido aumento em planos de saúde individuais ou familiares desde que presentes três elementos: 1) previsão contratual; 2) observação das normas dos órgãos governamentais reguladores; 3) ausência de percentuais desarrazoados ou aleatórios que onerem excessivamente o consumidor e discriminem o idoso. Destaca-se que, apesar da tentativa do STJ de coibir reajustes abusivos, o caso em tela teve o reajuste de $88 \%$ considerado legítimo. Casos como o destacado devem estar acompanhados de cautela pelo motivo de que o aumento desarrazoado não resulta simplesmente no impedimento da fruição de um serviço dentro da relação consumerista, mas acarreta também no próprio impedimento ao exercício do direito fundamental à saúde do idoso, dada a natureza desta relação, o que inviabilizaria sua própria permanência no plano, sobretudo quando já houvera contribuído por toda a vida e agora dele mais precisasse. As ideias de onerosidade excessiva e desvantagem exagerada previstas no parágrafo 1ㅇdo artigo 51 do CDC são aqui evidenciadas.

\footnotetext{
8 EMENTA: RECURSO ESPECIAL REPETITIVO. NEGATIVA DE PRESTAÇÃO JURISDICIONAL. NÃO OCORRÊNCIA. CIVIL. PLANO DE SAÚDE. MODALIDADE INDIVIDUAL OU FAMILIAR. CLÁUSULA DE REAJUSTE DE MENSALIDADE POR MUDANÇA DE FAIXA ETÁRIA. LEGALIDADE. ÚLTIMO GRUPO DE RISCO. PERCENTUAL DE REAJUSTE. DEFINIÇÃO DE PARÂMETROS. ABUSIVIDADE. NÃO CARACTERIZAÇÃO. EQUILÍBRIO FINANCEIRO-ATUARIAL DO CONTRATO. 1. A variação das contraprestações pecuniárias dos planos privados de assistência à saúde em razão da idade do usuário deverá estar prevista no contrato, de forma Documento: 66173014 - EMENTA/ACORDÃO - Site certificado - DJe: 19/12/2016 Página 1 de 3 Superior Tribunal de Justiça clara, bem como todos os grupos etários e os percentuais de reajuste correspondentes, sob pena de não ser aplicada (arts. 15, caput, e 16, IV, da Lei no 9.656/1998). 2. A cláusula de aumento de mensalidade de plano de saúde conforme a mudança de faixa etária do beneficiário encontra fundamento no mutualismo (regime de repartição simples) e na solidariedade intergeracional, além de ser regra atuarial e asseguradora de riscos. 3. Os gastos de tratamento médico-hospitalar de pessoas idosas são geralmente mais altos do que os de pessoas mais jovens, isto é, o risco assistencial varia consideravelmente em função da idade. Com vistas a obter maior equilíbrio financeiro ao plano de saúde, foram estabelecidos preços fracionados em grupos etários a fim de que tanto os jovens quanto os de idade mais avançada paguem um valor compatível com os seus perfis de utilização dos serviços de atenção à saúde. 4. Para que as contraprestações financeiras dos idosos não ficassem extremamente dispendiosas, o ordenamento jurídico pátrio acolheu o princípio da solidariedade intergeracional, a forçar que os de mais tenra idade suportassem parte dos custos gerados pelos mais velhos, originando, assim, subsídios cruzados (mecanismo do community rating modificado). 5 . As mensalidades dos mais jovens, apesar de proporcionalmente mais caras, não podem ser majoradas demasiadamente, sob pena de o negócio perder a atratividade para eles, o que colocaria em colapso todo o sistema de saúde suplementar em virtude do fenômeno da seleção adversa (ou antisseleção). 6 . A norma do art. 15, § 3ㅇ, da Lei no 10.741/2003, que veda "a discriminação do idoso nos planos de saúde pela cobrança de valores diferenciados em razão da idade", apenas inibe o reajuste que consubstanciar discriminação desproporcional ao idoso, ou seja, aquele sem pertinência alguma com o incremento do risco assistencial acobertado pelo contrato. 7. Para evitar abusividades (Súmula no 469/STJ) nos reajustes das contraprestações pecuniárias dos planos de saúde, alguns parâmetros devem ser observados, tais como (i) a expressa previsão contratual; (ii) não serem aplicados índices de reajuste desarrazoados ou aleatórios, que onerem em demasia o consumidor, em manifesto confronto com a equidade e as cláusulas gerais da boa-fé objetiva e da especial proteção ao idoso, dado que aumentos excessivamente elevados, sobretudo para esta última categoria, poderão, de forma discriminatória, impossibilitar a sua permanência no plano; e (iii) respeito às normas expedidas pelos órgãos governamentais: a) No tocante aos contratos antigos e não adaptados, isto é, aos seguros e planos de saúde firmados antes da entrada em vigor da Lei no 9.656/1998, deve-se seguir o que consta no contrato, respeitadas, quanto à abusividade dos percentuais de aumento, as normas da legislação consumerista e, quanto à validade formal da cláusula, as diretrizes da Súmula Normativa no 3/2001 da ANS. b) Em se tratando de contrato (novo) firmado ou adaptado entre 2/1/1999 e 31/12/2003, deverão ser cumpridas as regras constantes na Resolução CONSU no 6/1998, a qual determina a observância de 7 (sete) faixas etárias e do limite de variação entre a primeira e a última (o reajuste dos maiores de 70 anos não poderá ser superior a 6 (seis) vezes o previsto para os usuários entre 0 e 17 anos), não podendo também a variação de valor na contraprestação atingir o usuário idoso vinculado ao plano ou seguro saúde há mais de 10 (dez) anos. c) Para os contratos (novos) firmados a partir de 1/1/2004, incidem as regras da RN no 63/2003 da ANS, que prescreve a observância (i) de 10 (dez) faixas etárias, a última aos 59 anos; (ii) do valor fixado para a última faixa etária não poder ser superior a 6 (seis) vezes o previsto para a primeira; e (iii) da variação acumulada entre a sétima e décima faixas não poder ser superior à variação cumulada entre a primeira e sétima faixas. 8. A abusividade dos aumentos das mensalidades de plano de saúde por inserção do usuário em nova faixa de risco, sobretudo de participantes idosos, deverá ser aferida em cada caso concreto. Tal reajuste será adequado e razoável sempre que o percentual de majoração for justificado atuarialmente, a permitir a continuidade contratual tanto de jovens quanto de idosos, bem como a sobrevivência do próprio fundo mútuo e da operadora, que visa comumente o lucro, o qual não pode ser predatório, haja vista a natureza da atividade econômica explorada: serviço público impróprio ou atividade privada regulamentada, complementar, no caso, ao Serviço Único de Saúde (SUS), de responsabilidade do Estado. 9. Se for reconhecida a abusividade do aumento praticado pela operadora de plano de saúde em virtude da alteração de faixa etária do usuário, para não haver desequilíbrio contratual, faz-se necessária, nos termos do art. 51, § 2ㅇ, do CDC, a apuração de percentual adequado e razoável de majoração da mensalidade em virtude da inserção do consumidor na nova faixa de risco, o que deverá ser feito por meio de cálculos atuariais na fase de cumprimento de sentença. 10 . TESE para os fins do art. 1.040 do CPC/2015: O reajuste de mensalidade de plano de saúde individual ou familiar fundado na mudança de faixa etária do beneficiário é válido desde que (i) haja previsão contratual, (ii) sejam observadas as normas expedidas pelos órgãos governamentais reguladores e (iii) não sejam aplicados percentuais desarrazoados ou aleatórios que, concretamente e sem base atuarial idônea, onerem excessivamente o consumidor ou discriminem o idoso. 11. CASO CONCRETO: Não restou configurada nenhuma política de preços desmedidos ou tentativa de formação, pela operadora, de "cláusula de barreira" com o intuito de afastar a usuária quase idosa da relação contratual ou do plano de saúde por impossibilidade financeira. Longe disso, não ficou patente a onerosidade excessiva ou discriminatória, sendo, portanto, idôneos o percentual de reajuste e o aumento da mensalidade fundados na mudança de faixa etária da autora. 12. Recurso especial não provido (BRASIL, 2016).
} 
Em outras palavras, como o risco da administradora elevou-se em razão da idade, é chegada a hora de transferi-lo ao segurado por meio da elevação abusiva do valor da parcela e, caso não o suporte, poderá ser excluído da cobertura, até mesmo porque na análise da equação do custo e benefício sua permanência não seria mais interessante financeiramente para a administradora.

Em que pese a fundamentação do Superior Tribunal de Justiça no caso posto em tela, o precedente caracteriza grande risco ao consumidor idoso na medida em que a tênue linha do que é considerado "percentual desarrazoado ou aleatório" pode facilmente resultar em casos nos quais aumentos considerados legais acarretarão em desequilíbrios econômico-financeiros e inviabilizarão a manutenção do contrato, inviabilizando ainda o próprio direito à vida, conforme exposto alhures.

Por mais que se busque possibilitar o exercício da atividade empresarial, determinadas medidas, como os aumentos abusivos dos valores das mensalidades, vão de encontro à função social dos respectivos contratos de plano de saúde, apenas alimentando uma perversa lógica capitalista.

Ademais, a decisão em referência resgatou o vetusto princípio do pacta sunt servanda para a relação de consumo, subvertendo a premissa importante de que, na relação de consumo, a autonomia da vontade, sobretudo quando identificada a hipervulnerabilidade do segurado idoso nos contratos de planos de saúde, será sempre relativa, pelo reconhecimento da coação econômica do mesmo.

Da mesma forma, a decisão em comento convalidou uma espécie de autoridade decisória, quase que irrecorrível, da Agência Nacional de Saúde (ANS), que teria competência de avaliar os critérios de reajustamento dos planos de saúde por parte das operadoras privadas, deixando para uma pouco provável revisão judicial o reconhecimento de suposta onerosidade excessiva no caso concreto, subjetivando uma interpretação que deveria ser objetiva para o consumidor idoso em geral.

Não reconhecer a abusividade no aumento dos planos de saúde em razão da faixa etária pode significar também não reconhecer o direito à vida como valor sagrado no sistema jurídico e não conferir a proteção que necessita para coibir abusos e outras práticas nocivas.

Tais fatos levam à conclusão de que a decisão do STJ apresenta sério risco em termos de retrocesso jurisprudencial, pois tende a convalidar práticas empresarias dissonantes em relação aos ditames previstos no Código de Defesa do Consumidor e na Constituição Brasileira.

\section{CONCLUSÃO}

A decisão paradigmática do STJ no tema repetitivo 952, por meio do Acórdão proferido no REsp 1.568.244/RJ, seguiu na contramão do dirigismo contratual proposto pela Lei 8.078/90 (CDC), dando azo para a possível ocorrência de danos ao consumidor idoso, uma vez que sobrevalorizou a autonomia da vontade em detrimento do controle legal das cláusulas abusivas em contratos com administradoras de planos de saúde, que teriam maior liberdade no reajustamento das mensalidades conforme a variação da faixa etária do consumidor.

Outrossim, a decisão confere eficácia quase que absoluta às normas expedidas pela ANS quanto aos parâmetros técnicos para a aferição de eventual abusividade no aumento das mensalidades, enfraquecendo a possibilidade de discussão judicial de eventuais controvérsias.

Há um clima de desconfiança quanto à função mediadora do Estado no âmbito da Política Nacional das Relações de Consumo, pois tem dado claros sinais de que está num processo de distanciamento em relação ao consumidor, ${ }^{9}$ o que se comprova pela precarização da atuação administrativa das agências reguladoras, pela diminuição de suas competências, a influência política em decisões que deveriam se pautar exclusivamente por critérios técnicos, a falta de incentivos à atuação qualificada da sociedade civil na ocupação dos espaços políticos de deliberação, a fragmentação orçamentária dos órgãos de defesa do consumidor, etc.

\footnotetext{
${ }_{9}$ Nesse particular, o atual diretor de Desenvolvimento setorial da ANS, Rodrigo Aguiar, em recente declaração em entrevista ao jornal "O Globo" (UOL, 2018), afirmou que a agência tem o dever de proteger o sistema de saúde, e não apenas o consumidor.
} 


\section{Direito目

Conferir à Agência Nacional de Saúde (ANS) a prerrogativa de conduzir o debate jurídico qualificado quanto à avaliação da onerosidade excessiva dos planos de saúde, elevaria a desconfiança dos usuários do serviço, em especial dos consumidores idosos, reconhecidos como hipervulneráveis.

A transformação do direito a partir de uma base solidária, sobretudo do direito privado, resulta na adoção de uma forma de se humanizar o titular de interesses marginalizados pela opressão econômica, e de, efetivamente, promover as desigualdades jurídicas de tratamento, fundamentais na relativização de dogmas, como o da liberdade contratual, implicitamente fortalecido pela nova interpretação do STJ no julgamento em análise, sob o pretexto de justificar o equilíbrio econômico-financeiro das administradoras privadas.

Identificadas as dificuldades da pessoa idosa como consumidora, observa-se a necessidade de sopesar a maior densidade dos direitos em debate ao se analisar o acesso à saúde desta categoria de consumidores e os interesses econômicos das administradoras de planos de saúde.

Inviabilizar a revisão judicial dos contratos a partir da lógica de que a Agência Nacional de Saúde exerceria adequadamente sua função regulatória na análise dos aumentos reputados como abusivos, importaria em grave ameaça à manutenção do equilíbrio econômico-financeiro do contrato, trazendo a real possibilidade de ruptura forçada do vínculo contratual em franco prejuízo do consumidor.

É necessário reconhecer a ausência de liberdade decisória do consumidor quanto à contratação do plano de saúde privado, sua hipervulnerabilidade no momento de arcar com o aumento abusivo das prestações em razão do avanço de sua idade, a transferência do risco da atividade ao consumidor pelo desinteresse da operadora em manter segurados idosos em sua carteira de clientes, a involução da proteção administrativa ao usuário de serviços públicos e, agora, a interpretação do STJ que impede, a priori, a revisão judicial dos critérios de reajustamento das mensalidades dos planos de saúde por variação de faixa etária.

Precedentes como o decorrente do julgamento do REsp 1.568.244/RJ podem engendrar consequências negativas para o consumidor idoso, seja de ordem financeira (oneração excessiva das mensalidades e inadimplência), social (discriminação e marginalização) ou mesmo quanto à preservação de sua saúde, decorrente da suspensão dos serviços e, consequentemente, extinção do vínculo contratual.

A posição peculiar do idoso na sociedade brasileira o torna digno de uma tutela especial na ordem jurídica do consumo, sobretudo quando se reconhece que o próprio o direito à vida, consagrado como fundamental, somente pode ser efetivado ao idoso quando lhe são providas as condições de saúde necessárias para sua fruição adequada, algo inerente à própria função social do contrato aqui discutido.

\section{REFERÊNCIAS}

ANS admite falhas na fiscalização de planos de saúde: falhas na fiscalização ou na regulação? ASSETANS. 2 dez. 2012. Disponível em: http://www.assetans.org.br/redesocial/file/view/15712/ans-admite-falhas-na-fiscalizacao-de-planos-de-saude-falhas-na-fiscalizacao-ou-na-regulacao. Acesso em: 20 abr. 2017.

AREOSA, Silvia Virginia Coutinho. Idosos provedores: a importância dos recursos da aposentadoria para as famílias brasileiras. 2015. Disponível em: https://online.unisc.br/seer/index.php/barbaroi/article/view/5527/5244. Acesso em: 26 dez. 2016.

BRASIL. Tribunal de Justiça de Sergipe. Apelação cível no 2011214806. 2a Câmara Cível. Relator: Des. Osório de Araújo Ramos Filho. Data de julgamento: 11 out. 2011. Disponível em: http://www.tjse.jus.br/portal/consultas/jurisprudencia/judicial. Acesso em: 18 abr. 2017.

BRASIL. Superior Tribunal de Justiça. Recurso especial repetitivo no 1.568.244. 2a Seção. Relator: Ministro Ricardo Villas Bôas Cueva. Data de julgamento: 14 dez. 2016. Disponível em: https://ww2.stj.jus.br/processo/revista/inteiroteor/?num_registro=201600571401\&dt_publicacao=16/12/2016. Acesso em: 7 jun. 2017.

BRANCO, Paulo Gustavo Gonet. Direitos fundamentais em espécie. In: MENDES, Gilmar Ferreira; COELHO, Inocêncio Mártires; BRANCO, Paulo Gustavo Gonet. Curso de direito constitucional. 4. ed. rev. e atual. São Paulo: Saraiva, 2009.

BRÊTAS, Pollyanna. MPF apura omissão da ANS sobre problemas financeiros da Unimed-Rio. Jornal Extra. 29 out. 2015. Disponível em: http://extra.globo.com/ noticias/economia/mpf-apura-omissao-da-ans-sobre-problemas-financeiros-da-unimed-rio-17908316.html. Acesso em: 20 abr. 2017.

CAVALIERI FILHO, Sérgio. Programa de responsabilidade civil. 10. ed. rev. e ampl. São Paulo: Atlas, 2012.

CHAVES DE FARIAS, Cristiano; ROSENVALD, Nelson; BRAGA NETTO, Felipe Peixoto. Novo Tratado de Responsabilidade Civil. São Paulo: Atlas, 2015. 
CONSELHOS de medicina apontam falhas da ANS na avaliação da qualidade de prestadores de serviços e de planos de saúde. Sociedade Brasileira de Clínica Médica - SBCM. 2012. Disponível em: http://www.sbcm.org.br/v2/index.php/noticias/noticias-da-saude/2980-conselhos-de-medicina-apontam-falhas-da-ans-na-avaliacao-da-qualidade-de-prestadores-de-servicos-e-de-planos-de-saude. Acesso em: 20 abr. 2017.

CNJ. Conselho Nacional de Justiça. Justiça em números 2016: ano-base 2015. Brasília: CNJ, 2016. Disponível em: http://www. cnj.jus.br/programas-e-acoes/pj-justica-em-numeros. Acesso em: 20 abr. 2017.

DIAS, Lucia Ancona Lopes de Magalhães. Publicidade e hipervulneráveis: limitar, proibir ou regular? Revista de Direito do Consumidor, vol. 99, ano 24, p. 285-305, maio/jun. 2015.

FIGUEIREDO, Marcela Rodrigues Souza; SILVA JÚNIOR, Pedro Paulo Vieira da. A tutela do idoso frente às publicidades que incentivam o consumo de crédito. 2012. Disponível em: http://www.publicadireito.com.br/artigos/?cod=0efe32849d230d7f. Acesso em: 27 dez. 2016.

GALESCO, Felipe Gustavo. Operadoras não podem aumentar o valor do plano de saúde aos maiores de 60 anos de idade. 2014. Disponível em: http://www.migalhas.com.br/dePeso/16,MI196306,11049-operadoras+nao+podem+aumentar+o+valor+do+plano+de+saude+aos+maiores. Acesso em: 1ㅇmar. 2017.

IBGE. Instituto Brasileiro de Geografia e Estatística. Pesquisa Nacional por Amostra de Domicílios Anual. 2015. Disponível em: http://ftp.ibge.gov.br/Trabalho_e_Rendimento/Pesquisa_Nacional_por_Amostra_de_Domicilios_anual/2015/Sintese_Indicadores/Indicadores/01gerais_xls.zip. Acesso em: 22 dez. 2016.

MORAES, Maria Celina Bodin de. Danos à pessoa humana: uma leitura civil constitucional dos danos morais. Rio de Janeiro: Renovar, 2003.

MUCELIN, Guilherme Antônio Balczarek. A hipervulnerabilidade do consumidor deficiente no direito privado solidário: considerações iniciais sobre o diálogo entre o Código de Defesa do Consumidor e o Estatuto da Pessoa com Deficiência. In: FERREIRA, Vitor Hugo do Amaral; CARVALHO, Diógenes Faria de; SANTOS, Nivaldo (org.). Sociedade de consumo. Pesquisas em direito do consumidor. 2. ed. Goiânia: Espaço Acadêmico, 2016.

PROTESTE cobra da ANS solução para problemas de planos de saúde. PROTESTE - a nossa voz impõe respeito. 14 set. 2015. Disponível em: https://www.proteste.org.br/saude-e-bem-estar/plano-de-saude/noticia/proteste-cobra-da-ans-solucao-para-problemas-de-planos-de-saude. Acesso em: 20 abr. 2017.

PÜSCHEL, Flavia Portella et al. A quantificação do dano moral no Brasil: justiça, segurança e eficiência. Série Pensando o Direito, Brasília, n. 37, 2011. Disponível em: http://pensando.mj.gov.br/wp-content/uploads/2015/07/37Pensando_Direito1.pdf. Acesso em: 2 fev. 2017.

SANTANA, Nívia Cardoso Guirra; LIMA, Isabel Maria Sampaio Oliveira. A nova velhice do provedor. 2012. Disponível em: http:// www.uel.br/revistas/uel/index.php/mediacoes/article/viewFile/14029/11840. Acesso em: 27 dez. 2016.

SCHREIBER, Anderson. Novos paradigmas da responsabilidade civil: da erosão dos filtros da reparação à diluição dos danos. São Paulo: Atlas, 2013.

SCHMITT, Cristiano Heineck. O problema do reajuste de plano de saúde por mudança de faixa. 2016. Disponível em: http:// www.conjur.com.br/2016-set-14/garantias-consumo-problema-reajuste-plano-saude-mudanca-faixa. Acesso em: 10 mar. 2017.

SOMMER, Rudolf. Consumer's Mind - Die Psychologie des Verbrauchers. Frankfurt am Main: Deutscher Fachverlag GmbH, 2007.

TEPEDINO, Gustavo. O futuro da responsabilidade civil. Revista Trimestral de Direito Civil, vol. 24, 2005, Editorial. Disponível em: http://www.tepedino.adv.br/wp/wp-content/uploads/2012/09/RTDC.Editorial.v.024.pdf. Acesso em: 16 dez. 2016.

UOL. Não somos órgão de defesa do consumidor, diz diretor da ANS. 18 jul. 2018. Disponível em: https://economia.uol.com. $\mathrm{br} /$ noticias/redacao/2018/07/18/ans-consumidor-plano-de-saude-franquia-coparticipacao-regras-stf.htm?cmpid. Acesso em: 19 jul. 2018.

VERBICARO, Dennis. Consumo e cidadania. In: DIAS, Jean Carlos; KLAUTAU FILHO, Paulo (org.). Direitos fundamentais, teoria do direito e sustentabilidade. São Paulo e Belém: Método e Cesupa, 2009. p. 67-95.

VERBICARO, Dennis; ALCÂNTARA, Ana Beatriz. A percepção do sexismo face à cultura do consumo e a hipervulnerabilidade da mulher no âmbito do assédio discriminatório de gênero. Revista Pensamento Jurídico, São Paulo, vol. 11, n. 1, jan./jun. 2017.

VERBICARO, Dennis; PENNA João Vitor; LEAL, Pastora. O mito da indústria do dano moral e a banalização da proteção jurídica do consumidor pelo judiciário brasileiro. Revista de Direito do Consumidor, v. 114, ano 26, p. 75-99, nov./dez. 2017.

VERBICARO, Dennis; VERBICARO, Loiane da Ponte Souza Prado. A indústria cultural e o caráter fictício da individualidade na definição de consumidor-comunidade global. Revista Jurídica Cesumar, Maringá, v. 17, n. 1, jan./abr. 2017. 


\section{Direito: Debate}

VIEIRA JUNIOR, Wilson Marques. Idosos e planos de saúde no Brasil: análise das reclamações recebidas pela Agência Nacional de Saúde Suplementar. 2013. Disponível em: http://www.ans.gov.br/images/stories/Materiais_para_pesquisa/Materiais_por_ assunto/dissertacao-vieira-junior-idosos-e-planos-de-saude-no-brasil.pdf. Acesso em: 23 dez. 2016.

WHO. World Health Organization. Monitoring the health goal - indicators of overall progress. 2016. Available from: http:// www.who.int/gho/publications/world_health_statistics/2016/EN_WHS2016_Chapter3.pdf?ua=1. Cited: 25 dez. 2016. 